\title{
ANÁLISE DA ESTRATÉGIA DE DESENVOLVIMENTO REGIONAL SUSTENTÁVEL SOB A ÓTICA DO DESENVOLVIMENTO LOCAL: ESTUDO DE CASO DO MUNICÍPIO DE ERVÁLIA - MG
}

Viviane Angélica Caetano

Bacharel em Administração pela Universidade Federal de Viçosa - UFV

viviac2004@yahoo.com.br

\author{
Suely de Fátima Ramos Silveira \\ Pós-Graduação em Administração pela Universidade Federal de Viçosa - UFV \\ sramos1609@gmail.com
}

\author{
Alexandre Matos Drumond \\ Pós-Graduação em Administração Pública pela Universidade Federal de Viçosa - UFV \\ leamdle@hotmail.com
}

\begin{abstract}
RESUMO
O Desenvolvimento Sustentável e o Desenvolvimento Local, os quais juntamente com a Estratégia de Desenvolvimento Regional Sustentável compõem a fundamentação teórica deste artigo. Com base neste arcabouço teórico, analisa-se a Estratégia Negocial de Desenvolvimento Regional Sustentável (DRS) agenciada pelo Banco do Brasil (BB), por meio de um estudo de caso, em Ervália (MG) entre 2008 e 2010, cuja principal atividade econômica é a cafeicultura. Este estudo objetiva identificar a incorporação dos princípios de desenvolvimento local e sustentável pela Estratégia Negocial do DRS do banco; analisar os resultados alcançados por esta estratégia e verificar se no município estudado o DRS promove o desenvolvimento local sustentável. A metodologia utilizada pautou-se pela análise documental e entrevistas com os parceiros estratégicos do DRS na busca de suas percepções quanto ao alcance dos objetivos. Esta estratégia do banco está estruturada conforme os princípios de desenvolvimento local e sustentável, entretanto apresenta resultados incipientes quanto aos objetivos traçados. Ressalta-se que o BB desempenhou papel como mediador de conflitos locais e promotor de ações de desenvolvimento da atividade cafeeira. Conclui-se que o banco induz o desenvolvimento local, no entanto, são necessários esforços de monitoramento para alcançar seus objetivos e promover o desenvolvimento local e sustentável.
\end{abstract}

Palavras-chave: Desenvolvimento local. Desenvolvimento sustentável. Estratégia negocial de desenvolvimento regional sustentável.

\section{ANALYSIS OF THE SUSTAINABLE REGIONAL DEVELOPMENT STRATEGY FROM THE PERSPECTIVE OF LOCAL DEVELOPMENT: A CASE STUDY OF THE MUNICIPALITY OF ERVÁLIA - MG}

\section{ABSTRACT}

Natural resources have been used without proper concern regarding their maintenance and this use does not reflect a similar improvement in quality of life. In response to this, we drew up alternative proposals: Sustainable Development and Local Development, which are the theoretical foundations of this paper. This paper examines the strategy of the Sustainable Regional Development (SRD) of the Bank of Brazil (BB) through a case in Ervália/MG between 2008 and 2010, which has the main economic activity of coffee production. This article aims to identify the incorporation of the principles of the local development and sustainable development by the strategy of the BB, to analyze the strategy's results, and to verify if this program promotes the local and sustainable development in Ervália/MG. The methodology used was based on document analysis and interviews with the partners of the SRD regarding their perceptions about the achievement of objectives. The strategy of the BB is structured according to the principles of local and sustainable development; however, at this moment the results are incipient for the goals set. It is noteworthy that the BB has played a crucial role as a mediator in conflicts and a promoter of local development actions for coffee production. The BB induces local development, however, monitoring efforts and partners' envelopment are needed to achieve the objectives and promote local and sustainable development.

Key words: Bank of Brazil; Local development; Sustainable development. 


\section{INTRODUÇÃO}

As estratégias de desenvolvimento concebidas ao longo do tempo basearam-se na busca do crescimento econômico a qualquer preço, no consumismo e na destruição da natureza que, até pouco tempo, era considerada como fator abundante e inesgotável. A geração de lucros e resultados foi determinante para o sucesso das empresas e era por meio do crescimento econômico que se media o desenvolvimento de um país. No entanto, essa estratégia trouxe uma série de problemas e preocupações que atualmente comprometem tanto o desenvolvimento quanto o crescimento das nações (Hawken, 1999 apud Machado, 2002).

No ano de 1987, foi lançado um relatório pela Comissão Mundial sobre o Meio Ambiente e o Desenvolvimento da Organização das Nações Unidas (ONU), intitulado Nosso Futuro Comum, também conhecido como Relatório Brundtland. Esse relatório que, apresenta o conceito de desenvolvimento sustentável, tinha como objetivo estudar a relação entre o desenvolvimento econômico e a conservação do meio ambiente como forma de conter e até mesmo reverter os efeitos causados pelo crescimento e desenvolvimento desordenado.

Neste contexto, a sociedade se depara com um novo desafio: a busca de ações e inovações que ampliem a eficiência e a efetividade da sustentabilidade, revertendo os problemas de desigualdades sociais e da depredação ambiental. Essa estratégia deve ser executada de forma conjunta entre empresas, governo e sociedade civil.

O conceito de sustentabilidade, apontado por Machado (2002), está diretamente vinculado a uma relação entre o ser humano e a natureza, em que o meio ambiente deve ser conservado. Ampliando este entendimento, Sachs (2000) confere ao desenvolvimento sustentável o ideal ético, defendendo a responsabilidade de conservar a diversidade da natureza, de culturas e a sustentação da vida. Para isso, o autor apresenta cinco dimensões para sua constituição: social, econômica, ecológica, espacial e cultural. E ainda que essas dimensões são interligadas, interdependentes e devem estar em harmonia. Assim, quando alguma dessas dimensões não for atendida, não se pode considerar que o desenvolvimento sustentável foi atingido.

Atribuída ao mesmo período e relacionada com os princípios do Desenvolvimento Sustentável, surge uma nova proposta de desenvolvimento que compreende as especificidades e a diversidade das condições naturais e socioeconômicas de cada localidade: o Desenvolvimento Local.

Inserido em um ambiente marcado pela globalização que origina profundas transformações nas esferas produtivas, financeiras, políticas e comerciais, o desenvolvimento local, apesar de aparentemente parecer oposto à globalização, consiste em um processo simultâneo, em que a globalização encontra seu contraponto na valorização da dimensão local (Azevedo, 2004).

Buarque (1999) discute que o desenvolvimento local é um processo endógeno, registrado em pequenas unidades territoriais e agrupamentos humanos, capaz de promover melhoria da qualidade de vida e dinamismo econômico. Representa uma singular transformação nas bases econômicas, na organização social em nível local resultante de mobilização das energias da sociedade na exploração de suas capacidades e potencialidades específicas.

O Banco do Brasil (BB) é uma das instituições que possuem uma estratégia para indução do desenvolvimento local, por meio da mobilização de agentes econômicos, sociais e políticos, para apoio às atividades produtivas, priorizando regiões em razão dos seus baixos indicadores socioeconômicos. Esta estratégia consiste no Desenvolvimento Regional Sustentável (DRS), criado pelo BB em 2003 e executado por meio de suas agências bancárias distribuídas pelo território nacional. Esta estratégia foi expandida em julho de 2005 com a criação de uma Gerência Executiva de Desenvolvimento Regional Sustentável, ligada diretamente à Presidência do Banco.

A Estratégia Negocial de Desenvolvimento Regional Sustentável (DRS) objetiva contribuir com a geração de trabalho e renda e a adoção de práticas que elevem a qualidade dos indicadores de desenvolvimento social e ambiental, com soluções sustentáveis e participativas em conjunto com seus parceiros. Neste âmbito, a compreensão e análise das iniciativas que visam ao 
desenvolvimento sustentável e ao desenvolvimento local como alternativa econômica e social para comunidades e regiões excluídas do mercado globalizado tornam-se fundamentais.

O objetivo deste artigo é analisar a Estratégia de Desenvolvimento Regional Sustentável promovida pelo Banco do Brasil sob a ótica do Desenvolvimento Local e Sustentável no município de Ervália - MG.

Pretende-se, especificamente, analisar a metodologia do DRS do BB quanto aos princípios do Desenvolvimento Local e avaliar a sua aplicabilidade no município de Ervália, identificando as principais ações resultantes do DRS, a funcionalidade da metodologia, dos objetivos e de sua estratégia a partir da percepção dos parceiros envolvidos.

\section{FUNDAMENTAÇÃO TEÓRICA}

Este artigo possui como fundamentação teórica o processo de construção e significados dos conceitos de desenvolvimento sustentável e desenvolvimento local, assim como, apresenta nesta mesma seção a descrição e as diretrizes da estratégia de desenvolvimento regional sustentável do Banco do Brasil.

\subsection{Desenvolvimento sustentável}

As preocupações com sustentabilidade vêm de meados do século passado, Oliveira (2006) afirma que a partir da Segunda Guerra Mundial a preocupação com o crescimento econômico, em razão de não priorizarem a qualidade de vida, começou a se difundir.

Mas foi a partir do Relatório Brundtland, com a publicação do documento intitulado Nosso Futuro Comum, de 1987, que a Organização das Nações Unidas (ONU) assumiu o debate com maior intensidade, propondo uma mobilização mundial para o desenvolvimento sustentável. Fundamentou-se na constatação de que o modelo de crescimento econômico, até então adotado, havia gerado riqueza e fartura nunca antes vistas pelo Homem, mas às custas da miséria, da degradação ambiental e da poluição crescentes.

O Relatório Brundtland, elaborado pela Comissão Mundial sobre Meio Ambiente e Desenvolvimento, faz parte de uma série de iniciativas que reafirmam uma visão crítica do modelo de desenvolvimento adotado pelos países industrializados e reproduzido pelas nações em desenvolvimento e que ressaltam os riscos do uso excessivo dos recursos naturais, sem considerar a capacidade de suporte dos ecossistemas. Este documento propõe que o desenvolvimento sustentável é "[...] aquele que atende às necessidades do presente sem comprometer a possibilidade de as gerações futuras atenderem às suas necessidades".

Como Machado (2002) aponta, o conceito de sustentabilidade está diretamente vinculado a uma relação entre o ser humano e a natureza que, por sua vez, conserva o meio ambiente. Outra relação do conceito de sustentabilidade que pode ser feita é com o conceito de ética. Esta relação surge da preocupação da quantidade e da forma de se consumir atualmente os estoques naturais, com a imaginária necessidade de consumo pelas gerações futuras.

Sachs (2004) acrescenta que o trabalho é a única maneira de proporcionar melhores condições de vida para a população discriminada e excluída pela pobreza. "Igualdade, equidade e solidariedade estão, por assim dizer, embutidas no conceito de desenvolvimento" (Sachs, 2004, p.14). Apresenta-se, assim, a ideia de um crescimento alcançado por meio de empregos, com oportunidades de trabalho, com remuneração e boas condições de trabalho, ou seja, buscam-se estratégias de desenvolvimento que não se concentrem apenas na promoção de crescimento econômico alimentado por ganhos de produtividade do trabalho, mas aquelas que revertam a exclusão social.

Sachs (2000) sustenta que tanto a conservação quanto o aproveitamento racional da natureza podem e devem andar juntos, uma vez que todas as nossas atividades econômicas estão solidamente apoiadas no ambiente natural. Para que haja a inclusão social, Sachs (2004, p. 15-16) cita os cinco pilares do desenvolvimento sustentável:

Revista de Gestão Social e Ambiental - RGSA, São Paulo, v. 6, n. 3, p. 15-28, set./dez. 2012. 
a) Social: fundamental por motivos tanto intrínsecos quanto instrumentais, uma vez que diferenças sociais existem de forma ameaçadora sobre muitos lugares problemáticos do planeta, inclusive no Brasil;

b) Ambiental: sistema de sustentação da vida como provedor de recursos e como "recipiente" para a disposição de resíduos (muitas vezes produzidos desnecessariamente);

c) Territorial: relacionado à distribuição espacial dos recursos, das populações e das atividades;

d) Econômico: sendo a viabilidade econômica indispensável a um país;

e) Política: a democracia é um valor fundamental e um instrumento necessário para fazer as coisas acontecerem.

O conceito de desenvolvimento sustentável deve ser assimilado pelas lideranças, pelas empresas e pela sociedade como uma nova forma de produzir sem degradar o meio ambiente, estendendo essa cultura a todos os níveis das organizações, para que seja formalizado um processo de identificação do impacto da produção no meio ambiente e resulte na execução de um projeto que alie produção e preservação ambiental, com uso de tecnologia adaptada a esse preceito.

\subsection{Desenvolvimento local}

O Desenvolvimento Local é um processo de integração entre diversos setores produtivos e componentes socioculturais, que incentiva o empreendedorismo, apoia micro e pequenos empreendimentos e cultiva ambientes propícios para que novas iniciativas locais sejam criadas, com o intuito de gerar renda e riqueza para as populações de localidades com baixos índices de desenvolvimento (Serviço Brasileiro de Apoio às Micro e Pequenas Empresas [SEBRAE], 2000).

É a partir da década de 1990, com a reforma do Estado, que o discurso de desenvolvimento local se posiciona frente aos desafios postos pela globalização. Nesta etapa, o Estado incorpora um conjunto de inovações organizacionais e administrativas que vem sendo difundido em escala global. Este tipo de desenvolvimento representa, segundo Souza e Carvalho (1999, apud Azevedo, 2004), um processo que envolve atores políticos e sociais, estimula a participação das esferas do setor privado e da sociedade civil na formulação e implementação de políticas públicas.

Segundo Costa e Cunha (2002), o novo modelo de desenvolvimento passou a contemplar não apenas o crescimento da produção nacional como também a realização de avanços na qualidade de vida, na equidade, na democratização, na participação cidadã e na proteção ao meio ambiente.

O desenvolvimento deve ser entendido levando-se em conta os aspectos locais, aspectos estes que têm significado em um território específico. O global passa a ter sua importância associada ao local e vice-versa, já que ambos estão em constante mudança, provocada inclusive por suas inter-relações (Rist, 1996 apud Milani, 2005).

As mudanças assinaladas reforçam que o desenvolvimento adquire complexidade muito maior que o simples crescimento do produto e da renda, trata-se da percepção de melhorias na situação de vida, tanto individual quanto coletiva, dos atores sociais.

Braga (1999, apud Azevedo, 2004) acrescenta que em um mundo globalizado, a permeabilidade local às mudanças mundiais, para garantir integração e competitividade, passam a ser o foco central da agenda local e essa é a nova conotação que adquire a palavra desenvolvimento. É nesse contexto específico que nascem as propostas de "desenvolvimento local/endógeno".

Buarque (1999) reflete que os esforços de desenvolvimento local têm incorporado, de alguma forma, os postulados da sustentabilidade, procurando assegurar a permanência e a continuidade, no médio e longo prazo, dos avanços e das melhorias na qualidade de vida, na organização econômica e na conservação do meio ambiente.

Esta visão que valoriza o desenvolvimento local sustentável é dada como um possível caminho para a melhoria da qualidade de vida das populações e para a conquista de modos de vida mais sustentáveis. O desenvolvimento local é visto como uma estratégia de constituição de um ambiente produtivo inovador, na qual formas de cooperação e integração das cadeias produtivas e das redes econômicas e sociais se desenvolvem e se institucionalizam de tal modo, que ampliam as

Revista de Gestão Social e Ambiental - RGSA, São Paulo, v. 6, n. 3, p.15-28, set./dez. 2012. 
oportunidades locais, gerando trabalho e renda, atraindo novos negócios e criando condições para o desenvolvimento humano sustentável (Coelho, 2001).

A sustentabilidade do desenvolvimento requer a descoberta das potencialidades locais, no enfrentamento das desigualdades na esfera econômica. É essencial, portanto, criar condições favoráveis às negociações políticas e à mobilização social. Neste contexto, a estratégia de ação deve se concentrar na busca da equidade social, da preservação ambiental e da racionalidade econômica. Obviamente, sem esquecer a ampliação do regime democrático. É importante, portanto, considerar as características de cada região ou localidade, tendo em vista as realidades diferenciadas (Barreto, 2005).

Para que o desenvolvimento local sustentável ocorra, Azevedo (2004) argumenta ainda que a transferência de mais autoridade às administrações locais e a concessão de mais liberdade às organizações populares e não-governamentais pressupõe, além da autonomia local, uma população conscientizada, organizada e um governo local capacitado para o planejamento.

Sendo assim, o desenvolvimento local remete à ideia de uma economia flexível, capaz de adaptar-se aos dados mutáveis e constituir uma alternativa frente às grandes economias. A política do desenvolvimento local necessita igualmente de estratégias de financiamento e de formação, e passa pela descentralização dos níveis de decisão política, econômica e financeira (Benko, 1996, apud Azevedo 2004).

Neste sentido, Barreto (2005) chama a atenção para a situação dos produtores rurais que se encontram numa situação de impedimento de participação efetiva em nível de integração com o mercado. Nesta situação, torna-se fundamental o engajamento da comunidade na definição dos objetivos comuns a serem atingidos, pois se trata de um projeto coletivo. Sem dúvida, a presença da sociedade civil nas decisões governamentais tem contribuído para a consolidação do desenvolvimento nacional (urbano e rural) e da democracia.

Buarque (1999) ressalta ainda, a importância que essas iniciativas trazem para o papel desempenhado pelo governo municipal, de articulador de forças e atores locais para conjugar desenvolvimento econômico, promoção da cidadania e preservação ambiental, com base em práticas de parceria e na busca da negociação.

\section{A ESTRATÉGIA DE DESENVOLVIMENTO REGIONAL SUSTENTÁVEL (DRS)}

Em agosto de 2003, o Banco do Brasil (BB) criou um Grupo Técnico de Desenvolvimento Regional Sustentável, visando elaborar e implementar estratégias de atuação junto às comunidades, mobilizando agentes econômicos, políticos e sociais, de forma a impulsionar o desenvolvimento sustentável em determinadas regiões, priorizadas em razão dos seus baixos indicadores socioeconômicos, denominada de Estratégia Negocial de Desenvolvimento Regional Sustentável (DRS).

Como forma de incrementar e expandir a implementação da Estratégia Negocial DRS, em julho de 2005, foi criada a Gerência Executiva de Desenvolvimento Regional Sustentável, ligada diretamente à Presidência do Banco do Brasil. Em janeiro de 2007, foi aprovada a criação das Gerências DRS das Superintendências de Varejo, o que reforça a continuidade da implementação nos estados.

O Desenvolvimento Regional Sustentável (DRS) é uma estratégia do BB, que busca impulsionar o desenvolvimento sustentável das regiões onde o Banco está presente. A execução ocorre por meio da mobilização de agentes econômicos, sociais e políticos (Universidade Corporativa Banco do Brasil - UCBB, 2007).

Essa estratégia objetiva contribuir para a geração de trabalho e renda e para adoção de práticas que permitam um salto de qualidade nos indicadores de desenvolvimento social e ambiental. Essa ação conjunta aglutina os agentes da esfera federal, estadual e municipal, sociedade civil, políticos, empresários, profissionais liberais, entidades religiosas e ONGs e busca estimular os envolvidos a criarem soluções e conduzir o desenvolvimento regional sob a ótica da 
sustentabilidade, agregando assistência técnica, novas tecnologias, capacitação, consultoria, em todos os elos da cadeia de valor (UCBB, 2007).

A Estratégia Negocial de DRS se dá por meio do apoio a atividades produtivas, com a visão de cadeia de valor (desde que as atividades de produção e de entrega agreguem valor a produtos e serviços até o consumidor de destino), identificadas como vocações ou potencialidades nas diferentes regiões de atuação. A Estratégia DRS apoia o desenvolvimento de atividades nas áreas rurais e urbanas (agronegócio, comércio, serviço e indústria).

A atuação do BB, por meio da DRS, visa fortalecer o associativismo, a agricultura familiar, os pequenos empresários, as cooperativas populares, não excluindo os médios e grandes produtores rurais e as médias e grandes empresas, pois esses devem participar da estratégia. A proposta é promover o desenvolvimento regional sustentável e, para isso, todos os agentes e intervenientes da cadeia de valor de uma atividade produtiva devem participar.

Além de atuar como instituição de crédito, o banco também deve desempenhar o papel de agente catalisador de ações, fomentando, articulando e mobilizando agentes econômicos e sociais, identificando vocações e potencialidades das regiões, otimizando a capilaridade de sua rede de agências e incentivando a mobilização de seus funcionários. Essas ações requerem a democratização do acesso ao crédito, e até que o BB preste consultoria financeira visando agregar valor às ações dos parceiros.

Com base no diagnóstico, foi elaborado o Plano de Negócios DRS no qual são definidos os objetivos, as metas e as ações para implementação desse plano. A metodologia prevê ainda o monitoramento das ações definidas nos Planos de Negócios DRS e a avaliação de todo o processo. A Figura 1 apresenta, esquematicamente, a metodologia de DRS.

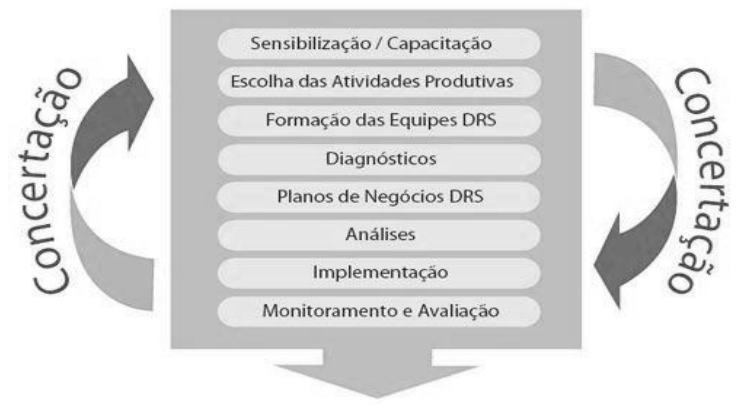

Figura 1 - Metodologia desenvolvimento regional sustentável

Fonte: Estratégia Negocial DRS. Universidade Corporativa do Banco do Brasil, 2007

As oito fases apresentadas na Figura 1 estão sequencialmente interligadas e são interdependentes. O início de qualquer uma dessas fases garante o término da anterior, de maneira a garantir a ação conjunta dos envolvidos para que se alcance o resultado esperado da metodologia.

\section{MÉTODO DE PESQUISA}

Esta pesquisa classifica-se como exploratória, visto que busca explicações a partir da análise da estratégia de DRS sob a perspectiva de desenvolvimento local. Consiste em um estudo de caso da estratégia de Desenvolvimento Regional Sustentável do Banco do Brasil no município de Ervália - MG. O estudo do DRS compreende o período de 2008 a 2010, cujo foco da estratégia DRS foi a atividade produtiva da cafeicultura. A escolha da agência do Banco do Brasil (BB) de Ervália se deu pela disponibilidade dos fatores que viabilizaram a realização da pesquisa.

A coleta de dados foi realizada em duas etapas: 1- Coleta de informação em sítios da Internet: Banco do Brasil, Instituto Brasileiro de Geografia e Estatística (IBGE), Instituto de Pesquisa Econômica Aplicada (IPEA), Empresa de Assistência Técnica e Extensão Rural de Minas Gerais (Emater-MG). 2- Inserções no campo de estudo - busca de informações por meio de entrevistas semiestruturadas para a comparação da realidade do estudo com a literatura levantada. 
O universo da pesquisa para análise da percepção dos parceiros estratégicos quanto à Estratégia Negocial do DRS em Ervália consiste em gestores e funcionários da agência do BB de Ervália, seus parceiros da estratégia e beneficiários. Por limitações operacionais e financeiras, não foi possível realizar as entrevistas abrangendo o conjunto total de atores envolvidos na implantação do DRS, optou-se, portanto, por uma amostra do universo da pesquisa.

As entrevistas ocorreram em dois momentos distintos, primeiramente foram levantadas as informações sobre a estratégia do DRS junto ao atual gerente da Agência de Ervália e com o antigo gerente, que iniciou a estratégia. No segundo momento, foram entrevistados representantes das entidades parceiras. Na figura 2, apresentam-se as entidades e seus representantes que compõem a amostra de entrevistados.

Para o tratamento de dados, adotou-se uma abordagem qualitativa do fenômeno, por meio da análise de conteúdo. Este método considera a interpretação de sentido que determinado indivíduo atribui às mensagens para avaliar a percepção sobre os resultados alcançados, as perspectivas e a contribuição da estratégia para o desenvolvimento local.

Conforme Oliveira (2007), a pesquisa qualitativa tem o intuito de explicar em profundidade o significado e as características do resultado das informações obtidas por meio de entrevistas ou questões abertas, sem mensuração quantitativa de características e comportamento.

\begin{tabular}{|c|c|}
\hline Entidade & Representante Entrevistado \\
\hline Banco do Brasil - Agência de Ervália & $\begin{array}{c}\text { Atual Gerente da Agência } \\
\text { Antigo Gerente da Agência }\end{array}$ \\
\hline Emater & $\begin{array}{c}\text { Técnico de Bem-Estar Social } \\
\text { Engenheiro Agrônomo }\end{array}$ \\
\hline Prefeitura Municipal de Ervália & Técnico em Agropecuária e Gestão Ambiental \\
\hline Sindicato dos Trabalhadores Rurais & Funcionário responsável pelo Crédito Fundiário \\
\hline Câmara dos Vereadores & $\begin{array}{c}\text { Vereador e presidente do Conselho Municipal de } \\
\text { Desenvolvimento Rural Sustentável }\end{array}$ \\
\hline Empresa Planejamento Rural e Assistência Técnica & Funcionária responsável pelo Programa Nacional de \\
(Prata) & Fortalecimento da Agricultura Familiar (Pronaf) \\
\hline Sindicato dos Produtores Rurais & Técnico Agropecuário \\
\hline Serviço Nacional de Aprendizagem Rural (Senar) & Ex-Técnico do Senar \\
\hline
\end{tabular}

Figura 2 - Entidades e seus representantes que compõem a amostra de entrevistados

Fonte: Elaboração própria

\section{CARACTERIZAÇÃO DO MUNICÍPIO DE ERVÁLIA - MG}

O município de Ervália (MG), criado em 1938, quando o distrito foi elevado à categoria de cidade, possui uma área de 357 quilômetros quadrados, localizado na mesorregião denominada Zona da Mata, sudoeste mineiro. Possui limites territoriais com os municípios de Araponga, Rosário do Limeira, Miradouro, São Miguel do Anta, Coimbra, Guiricema, Muriaé, São Sebastião da Vargem Alegre, São Geraldo e Canaã.

Ervália está situada a uma altitude média de 700 metros acima do nível do mar e conta, segundo dados do IBGE de 2010, com 17869 habitantes. O município possui 50\% de seu território montanhoso e sua zona rural distribuída em cinco comunidades: Dom Viçoso, Careço, Santa Terezinha, Ventania e Godinhos. O clima é caracterizado como tropical de altitude e o município é cortado pelas bacias do Rio Doce e Rio Paraíba do Sul.

$\mathrm{Na}$ economia, Ervália destaca-se pela produção de café, seu carro-chefe na produção agrícola; no setor industrial, se destaca a confecção e o setor de serviços é representado por um comércio diversificado. O Produto Interno Bruto (PIB) do município de Ervália em 2007 atingiu o patamar de $\mathrm{R} \$ 114.895 .802,00$, em que o PIB agropecuário contribuiu com 22,63\% dos valores desta produção. A atividade cafeeira é responsável por grande parte do PIB agropecuário, ao considerar a soma dos valores de produção do café, feijão e milho, a cafeicultura representa 78\%, gerando o montante R \$24166.640,00 em 2007, segundo dados do IPEA (2011).

Conforme os dados da Emater de Ervália, a atividade cafeeira está distribuída por todo território do município, sendo composta por $80 \%$ de propriedades de agricultura familiar e $20 \%$ de 
médio produtor rural. Possui uma área total plantada com café de 10.200 hectares, com uma produtividade média de 14 sacas/hectare. Esta produtividade é considerada baixa em relação à Zona da Mata, que tem produtividade em torno de 19,16 sacas/hectare. Considera-se que esta mesorregião desfruta de um bom potencial produtivo para a cultura do café em razão de sua aptidão climática.

Dada sua importância para a economia do município, a cafeicultura foi a atividade produtiva escolhida para a ação do Banco do Brasil, por meio da estratégia DRS. Esta estratégia de desenvolvimento regional prioriza a atuação em regiões com baixos indicadores econômicos e sociais, o município de Ervália não constitui uma exceção. Ao analisar o Índice Firjan de Desenvolvimento Municipal (IFDM) de 2007, Ervália se situa na 511ª posição do ranking estadual, apresentando para as dimensões Educação e Saúde índices inferiores à mediana calculada para o estado de MG, a Tabela 1 sintetiza estas informações (Firjan, 2010).

Tabela 1 - Índice Firjan de Desenvolvimento Municipal de Minas Gerais e Ervália

\begin{tabular}{cccccc}
$\begin{array}{c}\text { Índice Firjan de } \\
\text { Desenvolvimento } \\
\text { Municipal } \\
\text { Minas Gerais }\end{array}$ & IFDM Geral & $\begin{array}{c}\text { Emprego \& } \\
\text { Renda }\end{array}$ & Educação & Saúde & $\begin{array}{c}\text { Ranking } \\
\text { Estadual } \\
\text { - }\end{array}$ \\
$\begin{array}{c}\text { Mediana dos municípios } \\
\text { mineiros }\end{array}$ & 0,785 & 0,829 & 0,732 & 0,793 & - \\
\hline Ervália & 0,604 & 0,352 & 0,731 & 0,772 & $5^{\circ}$ \\
\hline
\end{tabular}

Fonte: Federação das Indústrias do Estado do Rio de Janeiro (2010)

Considerando o Índice de Desenvolvimento Humano (IDH), segundo o PNUD (2013), o município de Ervália apresentava, em 1991, um IDH de 0,375, refletindo baixo desenvolvimento. Já em 2000, apresentou ligeira melhoria, com IDH de 0,516. Em 2010, seu IDH atingiu 0,625, alçando o município para o nível médio de desenvolvimento.

\section{RESULTADOS E DISCUSSÃO}

Neste item analisa-se a estratégia DRS quanto aos princípios de desenvolvimento sustentável e desenvolvimento local, apresenta-se os objetivos do plano de negócios da estratégia, buscará identificar a percepção dos parceiros quanto aos objetivos do DRS e o papel desempenhado pelo Banco no desenvolvimento local.

\subsection{A análise da estratégia DRS quanto aos princípios de Desenvolvimento Sustentável e Desenvolvimento Local}

Para atender ao objetivo proposto, apresenta-se a análise da estratégia de DRS quanto aos princípios de Desenvolvimento Sustentável e Desenvolvimento Local. As fontes de informação para as descrições e análises foram os cadernos da Estratégia Negocial DRS da Universidade Corporativa do Banco do Brasil (2007) e o site do Banco do Brasil.

Por meio da metodologia do DRS busca-se que o processo de desenvolvimento local ocorra por intermédio de uma transformação singular nas bases econômicas, na organização social em nível local, resultante de mobilização da sociedade na exploração de suas capacidades e potencialidades específicas. Este intuito da metodologia está em consonância com a discussão de Buarque (1999) acerca do desenvolvimento local. A estratégia do DRS tenta, dessa forma, alcançar com a sensibilização, mobilização e capacitação dos envolvidos esse processo por meio do respeito às diversidades culturais, do desenvolvimento das capacidades e potencialidades específicas de cada região atendida.

A metodologia do DRS trabalha com essa concepção de desenvolvimento local sustentável, na busca por enfrentar os desafios e problemas econômicos, sociais e contemporâneos. Apoia o desenvolvimento de atividades nas áreas rurais e urbanas (agronegócio, comércio, serviço e indústria) de forma que ocorra uma continuidade, assegurando a permanência no médio e longo 
prazo dos avanços e melhorias na qualidade de vida, na organização econômica e na conservação do meio ambiente.

Desta forma, a estratégia do DRS acompanha a visão que valoriza o desenvolvimento local sustentável como um possível caminho para a melhoria da qualidade de vida das populações e para a conquista de modos de vida mais sustentada. O desenvolvimento local é visto como uma estratégia de constituição de um ambiente produtivo inovador, no qual formas de cooperação e integração das cadeias produtivas e das redes econômicas e sociais se desenvolvem e se institucionalizam, de tal modo que ampliam as oportunidades locais, gerando trabalho e renda, atraindo novos negócios e criando condições para o desenvolvimento.

\subsection{O Plano de Negócios de Desenvolvimento Regional Sustentável da Agência de Ervália}

A escolha da atividade econômica a ser trabalhada pela estratégia DRS da Agência de Ervália é a cafeicultura, por ser a atividade tradicional do município e a mais representativa economicamente. Outras atividades agrícolas desenvolvidas no município, como o milho e feijão, têm pequena representatividade, sendo atividades de subsistência nas pequenas propriedades de agricultura familiar.

Segundos dados da Emater de Ervália, o município possui cerca de 8.600 hectares de área plantada de café e mais 1.600 hectares que estão sendo reformados. O café Arábica, cultivado no município, tem, em média, a produção de 130 mil sacas, com uma produtividade de 14 sacas por hectare. A atividade tem grande representatividade na agricultura familiar e está dividida entre: pequenos proprietários, meeiros e parceiros.

De acordo com os dados do Banco do Brasil, a Estratégia Negocial do DRS da agência de Ervália atende 1.073 famílias e no plano está programado o volume de recursos de R \$14.305.700,00 para investimentos, dos quais o $\mathrm{BB}$ está programando fornecer $\mathrm{R} \$ 13.600 .000,00$, enquanto R \$705.700,00 advirão dos parceiros. O plano de negócios da agência de Ervália vem sendo conduzido em ritmo abaixo do previsto, segundo informações obtidas junto ao BB.

A Estratégia Negocial foi iniciada no ano de 2008, pelo gerente geral da agência que deu início ao desenvolvimento da estratégia. $\mathrm{O}$ referido gerente não se encontra mais na agência de Ervália, mas os objetivos propostos em seu plano de negócio estão em fase de implementação. Durante sua administração, reuniu os parceiros estratégicos do DRS para validar o compromisso com a estratégia.

No plano de negócio da agência, constam vários objetivos a serem alcançados (Figura 3), podendo ser alterados a qualquer momento, sem prejudicar a execução do plano de negócio.

\begin{tabular}{|c|c|}
\hline Áreas Temáticas & Objetivos \\
\hline Práticas de cultivo agrícola & $\begin{array}{c}\text { Aumentar a produtividade do café } \\
\text { Aumentar a margem de ganho do produtor } \\
\text { Adoção de técnicas conservacionistas }\end{array}$ \\
\hline Mobilização e participação & $\begin{array}{c}\text { Fortalecimento do associativismo } \\
\text { Organização das comunidades vinculadas }\end{array}$ \\
\hline Educação e cultura & $\begin{array}{c}\text { Redução do índice de analfabetismo } \\
\text { Criação do centro de inclusão digital }\end{array}$ \\
\hline Acesso ao crédito & $\begin{array}{c}\text { Atendimento da demanda por crédito } \\
\text { Efetivação de parcerias para o Pronaf } \\
\text { Oferta de crédito ao setor de transporte }\end{array}$ \\
\hline Infraestrutura & Melhoria das estradas \\
\hline
\end{tabular}

Figura 3 - Áreas temáticas e objetivos presentes no Plano de Negócio do BB para Ervália Fonte: Elaboração própria.

Como se trata de uma estratégia fundamentada nos princípios de prosperidade econômica, qualidade ambiental e justiça social, os objetivos trabalhados na metodologia têm de estar voltados para essas áreas. No caso do plano de negócios da agência de Ervália, percebe-se que todas as áreas: econômicas e sociais estão contempladas entre os objetivos, no entanto, há a predominância de objetivos econômicos e sociais. 


\subsection{Análise e percepção dos parceiros estratégicos quanto aos objetivos e a estratégia DRS}

Inicialmente, antes de relatar as opiniões dos entrevistados quanto a estratégia DRS deve-se pontuar algumas questões que chamaram a atenção durante a pesquisa: há falta de clareza dos entrevistados acerca da estratégia DRS, que é confundida com a estratégia do Conselho Municipal de Desenvolvimento Rural Sustentável (CMDRS) que está ligado a uma estratégia do Pronaf. O CMRDS foi criado com a finalidade de apoiar o desenvolvimento rural, fundamentado no fortalecimento da agricultura familiar como importante segmento produtivo gerador de emprego e renda, porém, não possui relação direta com a estratégia DRS.

As duas estratégias apresentam parceiros, finalidades e o desenvolvimento da agricultura familiar em comum, mas divergem quanto ao tipo de órgão incentivador, um ligado ao poder público e o outro, a iniciativa privada por meio do Banco do Brasil. As ações também divergem quanto a atuação, no caso do DRS está voltada para o desenvolvimento da atividade cafeeira, enquanto o CMDRS está voltado para todas as questões ligadas ao desenvolvimento rural das comunidades beneficiadas pelo Programa Nacional de Fortalecimento da Agricultura Familiar (Pronaf).

Outro ponto a ser levantado é a forte disputa partidária dentro do município que impede o fortalecimento de associações e mobilizações em busca de um objetivo comum, refreando ações como a da estratégia para o desenvolvimento local.

Ao se discutir sobre os objetivos do plano de negócios com os parceiros entrevistados, constatou-se que entre eles há elevado nível de desinformação quanto aos objetivos, a atuação de cada parceiro, resultando na afirmativa dos entrevistados que existe uma centralização, por parte do gerente da agência, na formulação do plano de negócios.

No entanto, existe a consciência, por parte de alguns dos parceiros, da impossibilidade de desenvolver um plano de negócios que chegasse a atender um objetivo comum, atribuído à divergência de opiniões e à divergência política. Verificou-se ainda, por parte de alguns parceiros, a valorização da iniciativa do gerente na mobilização e elaboração de um plano que trará benefícios para a comunidade.

Apresentou-se então, aos entrevistados, os objetivos do plano de negócios, agrupando-os segundo suas relações, de forma a serem mais claramente analisados e discutidos pelos parceiros.

O primeiro grupo de objetivos está relacionado às práticas de cultivo agrícola: aumento da produtividade do café, da margem de ganho do produtor e adoção de técnicas conservacionistas. De acordo com a percepção dos entrevistados, alcançou-se o consenso de que esses objetivos podem ser alcançados e que já estão sendo implantados, porém existe a necessidade de mais assistência técnica e de recursos financeiros para efetivação do objetivo.

De acordo com os técnicos entrevistados da Emater de Ervália, a própria empresa não consegue atender a demanda, pois o número de seus profissionais é insuficiente para o tamanho e a quantidade de propriedades que demandam os seus serviços.

O entrevistado, técnico da prefeitura, funcionário da Secretaria da Agricultura e Meio Ambiente, também reconhece o incipiente trabalho prestado, devido à insuficiência de profissionais que atendam a demanda. Ele afirma que:

[...] a assistência técnica é muito precária. Na nossa região, é muito precária e possui pessoal reduzido para demanda de serviço, são muitas propriedades que precisam da nossa assistência e nós não conseguimos atender a todos.

O segundo grupo de objetivos tratados está relacionado à mobilização dos envolvidos: fortalecimento do associativismo e organização das comunidades vinculadas. Novamente, os parceiros entrevistados apresentam informações consensuais: acredita-se na necessidade de se formar uma associação para que os pequenos agricultores tenham maior representatividade, conquistem mais espaço no mercado e somem esforços para o desenvolvimento da cafeicultura.

Revista de Gestão Social e Ambiental - RGSA, São Paulo, v. 6, n. 3, p.15-28, set./dez. 2012. 
No entanto, este processo não foi iniciado, porque alegam que um dos grandes obstáculos é a falta de cultura associativa, representada pela dificuldade de encontrar entendimento comum, o forte individualismo dos produtores e a divergência política.

$\mathrm{O}$ representante da Câmara de Vereadores entrevistado relata que a estratégia do BB conseguiu legalizar os conselhos dos povoados e reunir representantes, todavia pouco foi produzido, depois alguns conselhos das comunidades estão ativos e presentes nas reuniões do CMDRS, outros não têm representatividade. Ele comenta ainda:

[...] o pessoal tem um bloqueio muito grande, na própria comunidade quando eles vão se associar para fazer alguma coisa em benefício comum, se eles pensarem que um está levando mais benefício que o outro, que um produz mais, eles já não querem.

O técnico do Sindicato dos Produtores Rurais ainda insiste na questão da necessidade de haver lideranças das comunidades nos conselhos e não somente representantes, segundo ele deveria haver maior mobilização e iniciativa por parte dos interessados.

O terceiro grupo de objetivos está ligado à questão educacional e cultural: redução do índice de analfabetismo e a criação de um centro de inclusão digital. Esses dois objetivos ainda não foram implementados, mas os parceiros reconhecem sua necessidade e acreditam que esta é uma das maneiras de se iniciar um trabalho para melhorar as condições sociais dos produtores.

O técnico do Sindicato dos Produtores Rurais afirmou já ter obtido compromisso de entidades para doar os computadores para a ação de inclusão digital, porém ainda não foi identificado um local para o centro de inclusão digital e nenhum responsável pelos trabalhos de inclusão dos beneficiários.

O quarto grupo está ligado ao acesso ao crédito: atendimento da demanda de crédito, a efetivação de parcerias para operacionalização do Pronaf e a oferta de crédito para o setor de transporte. Dos objetivos traçados, este apresenta-se como o único operacionalizado dentro do prazo programado e que traz benefícios para os produtores de café.

O Sindicato dos Trabalhadores Rurais, a Emater, a Prefeitura, por meio da Secretaria do Meio Ambiente, a empresa Prata e o Sindicato dos Produtores Rurais conseguiram atuar nessa função dinamizando o acesso do pequeno produtor ao crédito, tanto fundiário como para custeio e investimento.

O funcionário do Sindicato dos Trabalhadores Rurais relata que, por meio da ação do DRS, o pequeno produtor tem acesso facilitado à terra por meio do crédito fundiário e tem havido grande procura. $\mathrm{O}$ funcionário do sindicato afirmou que tem havido grande procura por parte do agricultor para esta nova modalidade de crédito e boa aceitação e que os pequenos agricultores estão satisfeitos com aquisição dos terrenos e enfatiza a importância dessa ação. Ele afirma:

[...] eles (produtores) estão entendendo bem. Sabem que vão ter que produzir no terreno adquirido para estarem pagando, tem um bom entendimento. Estão achando ótimo o programa por conta do juro muito baixo, por estar ali adquirindo seu pedaço de terra. A maioria dos produtores, das famílias querem um pedaço para eles trabalharem.

Os técnicos da Emater também tiveram uma boa percepção desses objetivos e avaliam como um grande avanço para a agricultura familiar este acesso ao Pronaf. Descreveram que a efetivação das parcerias para operacionalização do Pronaf tem surtido efeito para atender a demanda por crédito, mas que ainda há muito a ser feito.

A funcionária da empresa Prata, responsável pela prestação de serviços na área técnica para disponibilização do Pronaf, também relata o aumento da demanda pelo crédito e dos benefícios gerados para a agricultura e o comércio do município.

O técnico do Sindicato dos Produtores Rurais realça a melhoria que o crédito tem proporcionado para as propriedades rurais pela aquisição de maquinário, do investimento na

Revista de Gestão Social e Ambiental - RGSA, São Paulo, v. 6, n. 3, p. 15-28, set./dez. 2012. 
lavoura, do acesso a novas técnicas de cultivo, já que existem algumas prerrogativas para o acesso ao crédito, tais como, a análise de solo, a análise foliar e outras práticas que garantam o bom investimento do recurso.

O quinto e último grupo possui um único objetivo, o de melhoria da infraestrutura das estradas. Os parceiros relatam as boas condições das estradas rurais que não são pavimentadas, mas que estão sendo mantidas em condições de trafegar.

Todos os entrevistados, a partir da análise dos objetivos e o discernimento quanto a CMDRS e DRS, acreditam nos benefícios para o desenvolvimento local por meio da estratégia DRS, todavia enfatizam a necessidade de uma maior mobilização dos envolvidos, a retomada da estratégia que se encontra parada por motivo de transferência de gerentes da agência local do BB e a necessidade de um esforço maior, por parte da comunidade, para reverter os efeitos negativos da política partidária. Enxergam o Banco do Brasil como principal agente a neutralizar os efeitos da política partidária, atuando como entidade pacificadora e mobilizadora dos interesses comuns da comunidade. Alguns parceiros já se sensibilizaram com a estratégia e buscaram, junto ao Banco, capacitação, motivados com a expectativa de resultados futuros para o desenvolvimento sustentável local.

\subsection{O papel do banco no desenvolvimento local do município de Ervália}

No caso do Banco do Brasil, a promoção de uma estratégia como do DRS fundamentada no conceito prosperidade econômica, qualidade ambiental e justiça social, pode acarretar ganhos para a comunidade muito além dessas esferas. Numa cidade como Ervália, na qual a economia gira principalmente em torno de uma única atividade, seu desenvolvimento tem longo alcance em todos os setores econômicos.

Isso ocorre porque, além da atividade movimentar muitos recursos no município, ela proporciona a distribuição de renda; fixa o homem no campo, diminuindo o êxodo rural; traz desenvolvimento do meio rural e do meio urbano; agrega valor à cadeia produtiva; além de mobilizar a comunidade para um objetivo comum.

O município de Ervália é reconhecido em toda região pela forte rivalidade partidária e os problemas acarretados por essa disputa, que não gera benefícios para a comunidade em geral, ocasiona desentendimentos e atraso do desenvolvimento local. Um dos resultados principais do banco com a estratégia DRS é como mediador desses conflitos, sendo uma entidade neutra, minimizando os efeitos negativos da política local.

O plano de negócios da agência de Ervália é construído com objetivos para o alcance da sustentabilidade e o desenvolvimento local por meio da cafeicultura. Alguma das ações propostas pelo plano já eram desenvolvidas no município pela atuação de outros órgãos. O banco inseriu essas ações em seu plano de negócio quando firmou compromisso com esses parceiros, de forma a fortalecer a sua estratégia. De fato, algumas ações desenvolvidas pela Emater, pela Secretaria da Agricultura e Meio Ambiente e por outros parceiros são independentes da estratégia DRS e ocorreriam com ou sem a parceria com o Banco.

Necessariamente, as ações que já ocorriam precisavam ser firmadas e solidificadas na estratégia DRS para dar sustentação a outras ações que viriam a contemplar o objetivo primordial, que é a sustentabilidade da atividade cafeeira para se chegar ao desenvolvimento sustentável do município. Não existiria maior demanda de crédito por parte dos produtores se não houvesse melhoria na produtividade do café ou aumento da sua margem de ganho. Ou, iniciativas de redução do analfabetismo e inclusão digital não seriam viáveis sem a mobilização ou organização das comunidades, nem mesmo poderia ocorrer o fortalecimento do associativismo.

\section{CONSIDERAÇÕES FINAIS}

A Estratégia Negocial do Banco do Brasil de Desenvolvimento Regional Sustentável (DRS) está pautada nos princípios de desenvolvimento sustentável e desenvolvimento local. Seus objetivos 
estão direcionados à melhoria da cadeia produtiva, na forma de alocação tanto de recursos financeiros como humanos.

No caso da agência de Ervália, foram verificados alguns pontos a serem trabalhados e melhorados para a continuação da estratégia de DRS. Primeiramente, as ações para adoção da estratégia experimentaram um período de paralisação devido a mudança da gerência do Banco do Brasil no município de Ervália, e em razão disso, houve uma descontinuidade dos objetivos almejados, em segundo lugar, verificou-se que os parceiros desconhecem o plano de negócio, existindo pouca mobilização, e também sinalizam a necessidade de capacitação dos envolvidos nas ações sobre a estratégia de DRS.

As dificuldades enfrentadas na mobilização dos parceiros estratégicos demonstram que os princípios da participação social não foram devidamente discutidos e muito menos aplicados. Os parceiros não participaram da elaboração das estratégias e dos objetivos do plano de negócios e ainda desconhecem os seus respectivos papéis para alcance dos objetivos propostos.

O Banco do Brasil se posiciona como articulador de entidades e da comunidade sem, no entanto, assumir diretamente as ações para alcançar o desenvolvimento local sustentável. A constatação de baixo nível de mobilização social remete à preocupação quanto à sustentabilidade da estratégia de DRS após a retirada do Banco do Brasil como principal articulador, visto que os parceiros estratégicos ainda não desenvolveram suas capacidades para a participação social.

Durante o estudo da metodologia do DRS verificou-se que o BB deveria monitorar as ações do DRS e, no caso de Ervália, existe a carência de avaliações periódicas de desempenho para reverter os pontos críticos indicados pelos entrevistados. Essas avaliações deveriam ser realizadas por uma equipe composta pelos envolvidos no DRS (Gerente, funcionários do BB e parceiros), de forma a mobilizar todos os stakeholders para o alcance dos objetivos propostos.

A estratégia DRS tem conseguido trazer benefícios para atividade cafeeira, promover a distribuição de renda e capacitar os beneficiários do programa, todavia ainda existem carências para o alcance de significativos resultados. Uma das principais ações a ser trabalhada deve ser a questão do associativismo para a mobilização dos beneficiários, de forma a conter as divergências mencionadas. Também deve-se dar mais atenção à assistência técnica para agricultura, que é insuficiente, conforme indicado pelos entrevistados, e, ainda, buscar o desenvolvimento de ações para a capacitação do produtor na área de gerenciamento da lavoura e beneficiamento do café, de forma a agregar maior valor ao produto.

No caso de Ervália, o papel do Banco do Brasil é importante para o desenvolvimento local, como mediador de conflitos, como fomentador da atividade econômica, sendo grande financiador e por mobilizar a comunidade.

Acredita-se que esta pesquisa exploratória possa inspirar outros estudos sobre implementação de planos de DRS como ação estratégica e um caminho para o desenvolvimento local.

Sugere-se que sejam realizados novos estudos nessa área, trabalhando com a perspectiva do beneficiário e dos gestores do banco em torno da discussão de seu papel e atuação em outras regiões alcançadas pela estratégia de DRS. Outras pesquisas também podem ser desenvolvidas em relação ao monitoramento do DRS, o acompanhamento e correção das ações para criar uma estratégia que promova o desenvolvimento sustentado.

\section{REFERÊNCIAS}

Azevedo, E. M. (2004) Desenvolvimento local sustentável: os projetos de execução descentralizada no Município de Abaetetuba-PA Uma experiência bem-sucedida? Revista Trilhas, Belém, ano 4(1), 69-84.

Barreto, M. C. (2005) Desenvolvimento local sustentável. Recuperado em: 20 set.2010, de: <http://www.cpafap.embrapa.br/embrapa/wpcontent/arquivos/2009/07/desenvolvimento_local_sust entavel.pdf $>$.

Revista de Gestão Social e Ambiental - RGSA, São Paulo, v. 6, n. 3, p. 15-28, set./dez. 2012. 
Buarque, S. C. (1999) Metodologia de planejamento do desenvolvimento local e municipal sustentável. Brasília: Projeto de Cooperação Técnica INCRA/IICA. (Apostila)

Coelho, F. D. (2001) Desenvolvimento local e construção social: o território como sujeito. In: Silveira, C. M., Reis, L. C. Desenvolvimento local: dinâmicas e estratégias. Rio de Janeiro: RITS.

Costa, F. L., Cunha, A. P. G. (2002) Pensar o desenvolvimento a partir do local: novo desafio para os gestores públicos. Congresso Internacinoal del CLAD sobre la Reforma del Estado y de laAdministración Pública, 7, Lisboa, Portugual. Recuperado em: 17 set.2010, de: <http://unpan1.un.org/intradoc/groups/public/documents/CLAD/clad0044418.pdf>.

Federação das Indústrias do Estado do Rio de Janeiro [Firjan] (2010) Índice Firjan de Desenvolvimento Municipal 2007. Recuperado em: 15 fev.2010, de < http://www.firjan.org.br/ifdm/consulta-ao-indice/consulta-ao-indicegrafico.htm?UF=MG\&IdCidade=312400\&Indicador=1\&Ano=2007>.

Instituto Brasileiro de Geografia e Estatística [IBGE] (2010) IBGE Cidades - Ervália: Síntese das Informações. Recuperado em: 18 ago.2010, de: http://www.ibge.gov.br/cidadesat/xtras/perfil.php?codmun=312400>.

Instituto de Pesquisa Econômica Aplicada [IPEA] (2011) IPEA Data. Recuperado em: 15 fev.2011, de: < http://www.ipeadata.gov.br> .

Machado, E. V. (2002) Desenvolvimento sustentável local: o caso de Canela. 95 f. Dissertação (Mestrado em Administração) - Universidade Federal do Rio Grande do Sul, Porto Alegre.

Milani, C. (2005) Teorias do capital social e desenvolvimento local: lições a partir da experiência de Pintadas (Bahia, Brasil). In: Capital social, participação política e desenvolvimento local: atores da sociedade civil e políticas de desenvolvimento local na Bahia. Escola de Administração da UFBA (NPGA/Nepol/PDGS).

Oliveira, G. B. de. (Org.) (2006) O Desenvolvimento sustentável em foco: uma contribuição multidisciplinar. São Paulo: Annablume.

Oliveira, M. M. de. (2007) Como fazer pesquisa qualitativa. Petrópolis: Vozes.

PNUD (2013) Atlas do desenvolvimento no Brasil. Recuperado em: 26 ago.2013, de: http://www.pnud.org.br/atlas/ranking/Ranking-IDHM-Municipios-2010.aspx.Sachs, I. I2000) Caminhos para o desenvolvimento sustentável. Rio de Janeiro: Garamond.

Sachs, I. (2004) Desenvolvimento: includente, sustentável, sustentado. Rio de Janeiro: Garamond. Serviço Brasileiro de Apoio às Micro e Pequenas Empresas (Sebrae/Bahia) (2000). Desenvolvimento local do Sebrae. Recuperado em: 22 out. 2010, de: http://www.ilhaboipeba.org.br/en/sebrae.html >.

Universidade Corporativa do Banco Do Brasil (UCBB). (2007) Estratégia negocial DRS. Brasília.

Recebido em: 13/03/2012

Publicado em: 21/12/2012 